\title{
Génesis e índole de la conversión de S. Agustín *
}

En este título el término «conversión» podría ser cambiado por «religiosidad». Los varios factores que determinaron el camino a seguir por S. Agustín, al mismo tiempo determinaron las características del tipo de religiosidad desarrollado en el recorrido de toda una vida. En este desarrollo confluyeron muchos impulsos. Antes de nada fue un proceso psíquico, proceso de integración e individuación en términos de la psiquiatría moderna. Fue también un conflicto entre sus amistades maniqueas y cristianas, tanto en el nivel personal como en el de la inspiración religiosa, lírica en sus años jóvenes y filosófica en sus años adultos. Está presente también la oposición entre la razón filosófica y las exigencias de sumisión a la fe, una fe profundamente enraizada en su alma. En este terreno entra en juego el problema, difícil para Agustín, de decidir entre el deseo de poder argumentar y demostrarlo todo (ideal no precisamente de los maniqueos pero sí del Agustín filosófico), y por otro lado el deseo de encontrar seguridad y paz interior en la entrega a una fe no demostrable. Fue, por último, un conflicto psíquico entre el apego a su madre Mónica y una protesta ambigua contra el predominio maternal. Este último conflicto probablemente ha estado en el origen de todo el desarrollo, como un fermento en la vida interior. Sólo un factor de este tipo puede explicar la enormidad del bloqueo emocional y las resistencias casi insuperables que Agustín mismo describe en muchísimas páginas de sus Confesiones.

Con todo esto ya queda dicho que en la conversión de S. Agustín no se trataba de un acontecimiento circunstancial, sino que fue la culminación de

* Conferencia dada por el Dr. Theo G. SINNIGE en el Estudio Teológico Agustiniano (Valladolid) el 25 de noviembre de 1987. 
un proceso psíquico que ya muchos años antes se había implantado en su alma. Como lo testimonian las Confesiones, escritas diez años después de la crisis emocional en el jardín de Milán, los elementos de la lucha interior seguían acompañándole, determinando el tipo de su religiosidad.

Ya desde hace siglos ha llamado la atención el carácter completamente nuevo y único de las Confesiones dentro de la historia de la literatura antigua. Muy pocas son las autobiografías en la tradición griega y latina, y muy raro es en la antigüedad el fenómeno de «conversión», sea como tema de literatura, sea como fenómeno religioso ${ }^{1}$. En las Confesiones de repente aparece una forma nueva de literatura, en la que el autor describe sus propias peripecias interiores como tantas fases en un desarrolio psíquico. El fenómeno es tanto más excepcional porque en estos siglos faltaba una psicología genética como la conocemos nosotros. $\mathrm{El}$ autor se ahonda en sus propias vivencias pasadas ofreciendo a sus lectores a la vez una nueva forma literaria y una nueva forma de religiosidad, una religiosidad interiorizada que tiene su centro en el corazón humano. ¿De dónde ha sacado la inspiración para esta manera de describir sus vivencias ahondándose en las raíces de su vida personal? ¿Dónde ha podido encontrar el prototipo de esta forma de religión interiorizada? Para encontrar una respuesta tenemos que buscar en los años de su formación intelectual y religiosa.

De nacimiento era católico. En las Confesiones (III 4,8) dice que había mamado la fe con la materna leche y que la llevaba dentro escondida en lo más profundo, - para decirlo con una expresión holandesa: era biológicamente católico-. Pero los años estudiantiles, que son el período de mayor receptividad en la vida humana, los había pasado en la comunidad maniquea. Ahora bien, en las Confesiones no menciona ninguna impresión ni ninguna emoción profunda que le haya venido desde la espiritualidad maniquea. Describe las amistades maniqueas, describe su desprecio y aversión actuales hacia la secta, y dice que se sentía muy defraudado porque los maniqueos resultaban no ser filósofos. Sobre lo que tenía de atractivo la vida con los maniqueos nada, y mucho sobre la mitología elemental y repulsiva, que le merece un desprecio duradero. Es inconcebible que este panorama de sus años jóvenes sea completo, y que un hombre de la talla de S. Agustín haya permanecido tantos años en la secta cuando faltaban completamente los encantos que ahondaran en sus convicciones y echaran raíces en su vida interior. Al escribir las Confesiones ya era obispo y no podía dar relieve a una inspiración auténtica que le hubiera

1. A.D. Nock, (Conversion. The Old and the New in Religion from Alexander the Great to Augustine of Hippo, Oxford 1933. J.M. LE BLOND, Les conversions de saint Augustin, Paris 1950. 
venido de la liturgia maniquea. Sin embargo, existía esta inspiración. Lo testimonian las nuevas fuentes descubiertas en el curso de este siglo, y que por primera vez desde la edad de los Padres de la Iglesia nos han permitido conocer desde dentro la manera de pensar y sentir de los maniqueos. Estos nuevos documentos han revelado la existencia dentro de la secta maniquea de una poesía verdaderamente religiosa e incluso una liturgia cristiana. Agustín debe haberlas conocido, pero no las menciona.

En el año 1893 se abrió una nueva época en la investigación del maniqueísmo. Se descubrió en el Turquestán chino toda una biblioteca de refugiados maniqueos. Los manuscritos son originarios de entre los siglos VI y VIII, pero contienen literatura maniquea más antigua. Por la mayor parte son traducciones del sirio al persa medio, al chino y al idioma turco de los Lliguros. Eran los primeros documentos que habían venido a nuestra disposición auténticamente maniqueos y nos ofrecen textos directamente accesibles, sin el rodeo por los Padres de la Iglesia. Hasta el año 1907 caravanas enteras iban transportando las toneladas de manuscritos, que ahora se encuentran en las bibliotecas de Londres y París ${ }^{2}$.

En los estudios que acerca de estas nuevas fuentes se publicaban en las revistas científicas se notaba con asombro el carácter cristiano de los himnos y la liturgia maniqueos. Al parecer los Padres de la Iglesia no habían visto o habían eclipsado, por exceso de celo, lo que verdaderamente había sido para los maniqueos meollo y raíz de la inspiración religiosa ${ }^{3}$. Esta primera impresión fue ampliamente confirmada por documentos igualmente numerosos e importantes, descubiertos esta vez en Egipto en el año 1930 y escritos en lengua copta. El hallazgo abarca dos obras importantes: un manual de teología maniquea con el título Kephalaia y una colección de textos litúrgicos, letanías y salmos. Para nuestro tema la parte más importante la forman estos «salmos maniqueos», editados y traducidos al inglés por C.R.C. Allberry ${ }^{4}$. La traducción

2. Véase mi contribución en el Congreso Agustiniano de Madrid (1987) bajo el título El maniqueísmo del joven Agustín y el relato de las Confesiones, en Jornadas Agustinianas. Con motivo del XVI Centenario de la conversión de S. Agustín. Madrid 22-24 de abril de 1987. Estudio Agustiniano, Valladolid 1988, pp. 71-87.

3. Información abundante en: E. WALDSChMIDT-W. LeNTZ, Die Stellung Jesu im Manichuismus, Berlín 1926 (Abh. preuss. Akad., Jahrgang 1926, philos.-hist. Nr. 4). El relato de los descubrimientos en: P. Alfaric, Les écritures manichéennes, Paris 1918, y en las extensas notas en el libro de Ch. M. PuEch, Le manichéisme. Son fondateur, sa doctrine, Paris 1949 (Musée Guimet, Bibl. de diffusion, 56) (trad. española Madrid 1957). Véase también: Fr. DECRET, Mani et la tradition manichéenne, Paris 1974 (Maitres spirituels, 40). F.C. BuRkITT, The Religion of the Manichees, Cambridge 1925.

4. C.R.C. Allberry, A Manichaean Psalm-Book. Part II, Stuttgart 1938. (La parte primera fue destruida en Berlín durante la guerra). H.J. Polosky-A. Böhlig-H. IBSCHER, Kephalaia, Stuttgart 1940. 
de Allberry es una obra maestra de poesía. De estos salmos voy a leerles algunos trozos, traducidos aquí del inglés al español. Agustín debe de haber conocido esta liturgia maniquea con su lirismo entrañable. Mi tesis es que precisamente la vertiente emocional y lírica que determina su tipo de religiosidad, le ha venido de los maniqueos ${ }^{5}$.

Los salmos maniqueos, en la admirable edición de Allberry, abarcan un total de 233 páginas en folio. Gran parte de estos salmos pertenecen a una colección llamada «salmos de Jesús». De esta colección vienen los fragmentos que siguen aquí:

p. 173: «En mi espíritu habitas tú, mi alma es el lugar de tu alegría ... Tú eres el rey de mi alma, oh Espíritu Santo».

El poeta quiere decir que el alma del creyente sabe por testimonio interior que el Espíritu Santo obra en ella y le da la alegría de la vida divina. La doctrina del Espíritu Santo como elemento esencial de la teología maniquea se ve confirmada por textos del manual de teología, los Kephalaia, p. ej. p. 35: «La primera fuerza que El (el Padre) llamó, es el Espíritu de la Luz, Padre de todos los Apóstoles, Primero en todas las Iglesias». Y p. 182: «El Espíritu de la Luz, que procede del Cristo amado y que el Cristo envió a la santa Iglesia, este Espíritu es también una carta de paz. En esta carta se halla escrita toda revelación y toda sabiduría».

Es decir, que el Espíritu, enviado por Jescuristo, transmite a la Iglesia la revelación de los misterios y asegura la paz. Se nota que en la teología maniquea funcionaba el concepto de Iglesia. La sabiduría del Espíritu Santo está incorporada a la Iglesia de los Santos.

Se encuentra también la doctrina del Cristo Cósmico, tan fundamental en S. Pablo:

«Yo estoy presente en todas las cosas. Yo sustento los cielos. Yo soy el fundamento en que se apoya la tierra. Soy la luz que emana y que alegra las almas. Yo soy la vida del mundo» (Salmos p. 54). Son obvios los paralelos con Pablo y Juan, p. ej. Colosenses 1,15-17: «en El (Cristo) fueron creadas todas las cosas, y todo tiene en El su consistencia», como también con el cuarto evangelio ${ }^{6}$.

En el sentimiento religioso de los salmos destacan muchos elementos de origen gnóstico. En la religión gnóstica el mensaje de salvación no le viene al creyente por la mediación de los apóstoles u otros testigos, sino que la llamada interior y el despertar del alma son decisivos para la fe del creyente. Esta par-

5. P.J. DE Menasce, AUgustin Manichéen, Freundesgabe Ernst Robert Curtius, Bern 1956, p. 79-93.

6. También: 1 Cor 8,6 y Heb 1,2 . 
ticularidad determina el carácter típico del sentimiento religioso interiorizado como también lo encontramos en S. Agustín.

En un salmo, que puede haber formado parte de una liturgia de los moribundos, encontramos un alma que se prepara al momento de despedirse (p. 53). Jesús le dice al alma: «Consuélate, reprime las lágrimas, alma querida, porque has puesto el fundamento de tu fortaleza sobre la roca que es Cristo, has encendido tus lámparas en el aceite de la fe». Y el alma: «Oh Señor, la àlegría de tu dulce voz me hace olvidarme de la vida; la dulzura de tu voz me hace acordarme de mi patria. ... Oh Espíritu glorioso proveniente de Jesús, ayúdame, sí, ayúdame a mí, porque estoy suspendido de ti, tú apaciguas el miedo a la muerte por tu cruz victoriosa».

Otro ejemplo en p. 57. El alma dice: «Renuncié al mundo con sus desvíos, he amado a mi Salvador, desde mi juventud he rezado, ayunado, dado limosnas. Ahora ven, oh mi Señor Jesús, ayúdame». Y viene la respuesta: «Enhorabuena, oh alma atareada, que has terminado tu lucha y conquistaste el poder de los Arcontes ${ }^{7}$, el cuerpo y sus pasiones. Recibe de manos de tu juez la corona, recibe los dones de la luz, sube a tu reino y a tu reposo».

El tema de la llamada interior es frecuente en las varias corrientes gnósticas. El alma tiene que ser despertada por una voz interior, que viene de Dios y que en un momento decisivo conmueve al alma para convertirla a la Luz. Así p. ej. p. 57: «La Luz brilló para ti, oh tú que duermes en el infierno [ = en este mundo de materia] y es la sabiduría del Paráclito, el rayo de luz. Bebe el agua del recuerdo, rechaza el olvido. El que está herido y quiere recobrarse, que acuda al médico».

En este mundo material el olvido y el error han tenido hechizada al alma. Para encontrar la iluminación interior invoca a su Salvador (p. 56): «Ven, oh Señor Jesús, Salvador de almas, que me has puesto a salvo de la ebriedad y el error de este mundo. Tú eres el Paráclito, te he amado desde mi niñez. Dentro de mí resplandece tu luz como farol rutilante. Tú has desechado de mí el olvido y el desvío, tú me has enseñado a bendecir a Dios y sus Luces».

Muchos de los salmos pueden clasificarse como salmos de despedida de los moribundos. Son probablemente el prototipo de lo que los maniqueos de la Edad Media llamaban el consolamentum ${ }^{8}$, ritual que sustituía a la extrema unción. Los maniqueos no admitían sacramentos.

Los textos dan testimonio de una fe entrañable, que se presenta como entrega personal. Esta fe se mueve dentro de una teología completamente cristiana. Álgunos ejemplos más:

p. 62: el alma dice: «Me fue dado ver la Luz; por eso no me importan las

7. Los Arcontes son los malos espíritus que reinan bajo la Luna.

8. Steven Runciman, The Medieval Manichee, Cambridge 1947, reprint 1982, p. 163-166. 
tinieblas. Que nadie llore por mí. He aquí que las puertas de la Luz se abren delante de mí».

p. 93: «¿Quién pudiera verlo, oh mis hermanos, y volver a la tierra para decirles a todos la gloria que hoy recibí? Os imploro a todos, oh mis hermanos, mis familiares, no lloréis por mí, porque he encontrado la recompensa de mis labores».

p. 61: «Oh Jesús, Luz de los fieles que a ti se acogen, te imploro, no me abandones.

La hermosísima imagen, que es mi Padre, permíteme descubrirla y ver tu resplandor incorruptible, confirmación de mi alma.

Veo una muchedumbre despiadada como los buitres que me acechan. Oh Jesús, manifiéstate a mí en el día de mi necesidad. Destruye las redes de la congoja, la compañía de estos necios. Guarda tu oveja con tu Luz de los lobos salvajes y devastadores.

Descubre tu cara a mí, el Esplendor santo e incorruptible, porque tú eres mi buen pastor, mi médico verdadero y piadoso"».

En este texto el Padre es Jesús, que los maniqueos llamaban Padre del alma. La imagen es el Verbo, imagen perfecta del Padre Eterno. Estar incorporado a este imagen/Verbo asegura la salvación al alma.

p. 75: « Sálvame, oh Cristo de la bendición, Salvador de las almas santas. Subiré a los cielos y en esta tierra abandono mi cuerpo. Suenan los clarines, los oigo, están citándome para agregarme a los inmortales.

Rechazo mi cuerpo dejándolo en la tierra de la que fue compuesto. Desde mi niñez aprendí a caminar en el camino de Dios.

Que nadie llore por mí, ni mis hermanos ni los padres que me engendraron. Mis verdaderos Padres ${ }^{9}$, los que están en las alturas, éstos aman mi alma y están buscándola».

Los textos presentan el simbolismo corriente dentro de la secta maniquea: Jesús el Esplendor del Padre Eterno, el buen pastor y médico de las almas, la vejez y enfermedad de esta vida, el barco que traslada las almas hacia la fuente de la Luz. Está claro que aquí no hay nada de iranismo, porque falta todo elemento que pudiera considerarse como importado del Oriente. Tampoco pueden interpretarse los textos como adaptación de una religión oriental al cristianismo occidental.

p. 81: «Las puertas del firmamento se abren delante de mí y pasan por éstas los fulgores de mi Salvador, el semblante glorioso de la Luz.

He dejado mi vestidura en la tierra, la vejez y las enfermedades que llevaba dentro. Me he puesto la estola de la inmortalidad.

9. Dios Padre y el Hijo. 
Embárcame hacia el sol y la luna, oh embarcación de luz que estás en paz encima de estas tres tierras».

La colección de salmos ofrece también ejemplos de oraciones en forma de letanía, probablemente destinadas a la celebración litúrgica. Los dos ejemplos que siguen tienen invocaciones repetidas por los circunstantes.

p. 63: «Cristo, mi novio, me llevó a su cámara nupcial. Descansé con Él en la tierra de la inmortalidad. - Oh mis hermanos, recibí mi corona.

Miré mi tierra, encontré a mis Padres ${ }^{10}$, los piadosos se regocijaron conmigo, mis Eones me dieron la bienvenida. - Oh mis hermanos, recibí mi corona.

Gané un lucro, oh mis hermanos, que nadie puede robármelo, un tesoro imperecedero, al que no se encaminarán ladrones. - Oh mis hermanos, ...

Soy como una oveja que está buscando su pastor; encontré mi verdadero pastor, él me reintegró al rebaño. - Oh mis hermanos, ...

He aquí que he llevado a cabo la lucha; he aquí que arrimé mi barco a la ribera; no lo destruyó el temporal, no lo agarraron las olas».

p. 158-159: «El Reino es Amor, esta paloma blanca. No es ni oro ni plata, no es un comer y beber, pues el Reino de Dios no está en una muchedumbre, sino que al Reino hay que darle sitio dentro de tu alma ${ }^{11}$...

... Gustad y ved cómo es dulce el Señor. Cristo es palabra de la Verdad, quien la oye vivirá.

Gusté de un dulce sabor, comprobé que nada es más dulce que la palabra de Verdad. - Gustad ...

Gusté de un dulce sabor, no encontré nada más dulce que el nombre de Dios. - Gustad ...

Gusté de un dulce sabor, no encontré nada más dulce que Cristo.

¿Dónde hay una madre amable como la mía, Amor?

¿Dónde hay un padre amable como el mío, Cristo?

¿Qué miel tan dulce como este nombre, Iglesia?

La sabiduría te invita comer con el Espíritu.

Se adereza el nuevo vino, se distribuyen lo vasos.

$\ldots$

Un corazón santo crea en mí, oh mi Dios, y un espíritu firme renueva dentro de mí.

El corazón de la santidad es Cristo; si El resucita en nuestra alma, también nosotros resucitaremos con Él.

10. El Padre Eterno y el Hijo, Jesús, también llamado Padre.

11. Religión interiorizada. 
Cristo ha resucitado, los muertos con Él resucitarán; si en Él creemos, pasaremos más allá de la muerte y hallaremos la vida».

El lirismo religioso de los salmos se hace patente por todas partes. De la abundancia de esta poesía dos ejemplos más, para completar el panorama.

p. 58: «Sustentaos el uno al otro, hermanos míos, no vaciléis: tenemos un Dios que nos quiere, Él nos ayudará según su misericordia».

El optimismo y la vitalidad de la religión maniquea se hacen notar también en el amor a la buena música. Lo que dice S. Agustín en las Confesiones es esto, el amor a la música, el único punto positivo mencionado acerca de la vida dentro de la secta maniquea. Aún lo dice de pasada (III 7,14: et cantabam carmina). En uno de los salmos (p. 164) leemos estas líneas encantadoras:

«Hermanos míos, hagamos fiesta y cantemos a nuestro Salvador, que nos rescató del engaño; tened un corazón que no se cansa de cantar».

La religiosidad interiorizada de estos salmos maniqueos halla su eco a lo largo de todo el relato de las Confesiones. Como ya se ha dicho arriba, el género literario era nuevo y nuevo era el presentar el propio desarrollo emocional como una batalla ordenada a conquistar la fe. En los Padres de la Iglesia anteriores a S. Agustín no se encuentran descripciones parecidas de la lucha de un alma cristiana. La unicidad tanto del estilo literario como del contenido de esta historia de su mundo interior no se explica con sólo decir que fue la creación de un genio. Existía, sin embargo, una comunidad de creyentes que consideraba la emoción personal e íntima como signo distintivo de la autenticidad del sentimiento religioso. Dirigirse no por mensajes que vinieran del mundo exterior, sino por el mensaje interior es típico de la tradición gnóstica y maniquea. Parece probable que todo el concepto de autobiografía religiosa le haya venido a Agustín de la comunidad de los maniqueos que localizaban el centro de toda la religión en la vivencia íntima. El único contexto en el que se puede enmarcar el estilo de las Confesiones es esta tradición, en la que el testimonio del alma, la conversión y la entrega del corazón eran los determinantes de la vida religiosa.

Veamos ahora los testimonios de esta actitud que nos ofrecen las páginas de las Confesiones.

Para Agustín Dios no es el resultado de unas abstracciones filosóficas sino una presencia viva e íntima. Al describir los desvíos de sus años jóvenes, le pone a Dios la pregunta: ¿dónde estabas entonces?, y Agustín mismo da la respuesta: «estabas dentro de mí y más interior que lo más íntimo mío» (III $6,11)$.

Al describir la dependencia de las criaturas de Dios, dice que Dios creó las almas, pero no de manera que las hiciera y se marchase, sino que está dentro de nuestro corazón, aun cuando el corazón está errando fuera de Él (IV 
12,18). Mirando atrás en el libro $\mathrm{X}$, después de terminada la historia de su conversión (X, 27,38), dice: «Tarde te amé, y eso que estabas dentro de mí». Por eso, buscar a Dios supone profundizar en su propio corazón (X 24,35): «Cuántos caminos no he recorrido dentro de mi memoria buscándote a ti, y fuera de mi memoria no te encontré». Para buscar a Dios hace falta entrar dentro de sí mismo (VII 10,16): «fui amonestado a volver a mí mismo, me convertí adentro y entré en mi interior para ver con los ojos del alma la luz inconmutable». Así describe Agustín cómo empezaba à encontrar el camino que le iba a conducir a la conversión. En otro lugar describe el aturdimiento de que fue víctima cuando todavía no había encontrado su norte, y dice: «yo mismo era el lugar de mi desastre. ¿A dónde podía escapar mi corazón de mi corazón, a dónde huir de mí mismo, donde no me acompañara yo a mí mismo?» (IV 7,12).

En los libros que añadió Agustín a la historia íntima de su conversión (Conf. X-XI-XII-XIII) a menudo se repite este tema. El testimonio de la .fe viene $a b$ intus, de la profundidad del alma - tema perfectamente gnóstico(XII 8,10): «así en el Evangelio el Verbo habló en forma carnal, y esta palabra se hizo percibir por las orejas para que por dentro se buscase este Verbo"». Dios habla a quien con el oído interior le escucha (XI 9,11): «Que todo el que pueda te escuche al hablarle Tú en su alma», y tres veces lo repite en otro capítulo (XII 11,11-12): «me lo dijiste Tú, Señor, en voz alta al oído interior». Hallamos aquí reproducido el tema gnóstico del mensaje interior. La presencia de Dios se hace sentir dentro del alma como voz que lleva un mensaje y como luz que ilumina. Hablando de la inspiración de los profetas, invoca a Dios, «que eres, oh Dios mío, la dulce luz de mis ojos escondidos», es decir, que se percibe la presencia de Dios por los sentimientos escondidos en la profundidad del alma.

En marcado contraste con esta vertiente de la religiosidad de Agustín está la actitud que observamos en los libros escritos inmediatamente después de la crisis del año 386. Son los Soliloquios y los Diálogos de Casiciaco, obras todas de los meses finales del año 386. El proceso de su conversión ha pasado por la crisis, pero iba a durar todavía por muchos años. Había superado las resistencias que le impidieron entregarse, pero con la voluntad de entrega no le venía sin más la seguridad deseada. Se pone a buscar argumentos, y es muy característico el que en este momento lo hace por el método de la duda académica y el diálogo filosófico. Ya en años anteriores le había entusiasmado una obra filosófica, el Hortensio de Cicerón (Conf. III 4,7). Cuando se había trasladado a Milán el proceso se repitió, ahora al conocer la metafísica de Plotino (Conf. VII 9,13-15). En ambos casos se trataba no de unas conclusiones a las que le hubieran conducido sus propias elucubraciones filosóficas, sino que estaba 
obsesionado por problemas a los que le ofrecieran soluciones los escritos de otros filósofos. Detrás de las soluciones filosóficas se hacía sentir, sin embargo, lo que en última instancia estaba buscando: la seguridad. El proceso psíquico que se resolvió en la crisis del año 386 no era de ninguna manera un buscar solución a problema filosóficos, como tampoco era un buscar argumentos para creer. Como él mismo lo dice, era católico desde la niñez (Conf. V 10,20; VI 3,4), y también dice que ya había hallado motivos para creer (VII 9,13-14). La crisis del 386 significaba el abrirse paso a una entrega, reconocer los fundamentos de su propia existencia y así encontrar las bases de certeza. Este afán ya se había manifestado anteriormente, acompañado de una preferencia por argumentos racionalistas. Al final del libro $\mathrm{V}$ dice que había rechazado a los maniqueos, a los que anteponía ya algunos filósofos, y se decidió a quedarse como catecúmeno, hasta que apareciera algo cierto. Cuando le atormentaban las dudas y el conflicto interior, se abstenía de asentimiento, y como consecuencia le mataba la incertidumbre (Conf. VI 4,6). Buen ejemplo de la nueva propensión hacia las fórmulas filosóficas ofrece la conocida plegaria en el capítulo primero de los Soliloquios. El texto marca una invasión de la terminología filosófica en el pensamiento de Agustín, y es casi una letanía filosófica. Invoca a Dios como Verdad y Vida, como el Bien y la Belleza, como la Substancia verdadera, como Luz inteligible, términos que frecuentemente se encuentran en las Enéadas de Plotino. Dios es, en buena tradición cristiana, el creador del universo, pero le presenta en terminología platónica: el Dios, según cuyas leyes giran los cielos, y por quien todas las cosas tienden al ser, expresión alquilada directamente de Plotino ( $i, 1,3)$. Advertimos un concepto extravertido de Dios, muy opuesto al concepto del Dios íntimo de las Confesiones. Estamos ante un cristianismo neoplatónico, y no hay que maravillarse cuando varios autores modernos han expresado la opinión de que la conversión de Agustín fue en primer lugar una conversión a la filosofía ${ }^{12}$. Como lo veremos, fue probablemente una fase transitoria, porque en las obras de la edad madura de Agustín podemos observar las dos cosas: Una religiosidad íntima y emocional, y también teorías racionalizadas en términos bien definidos.

El equilibrio alcanzado en la crisis del 386 era un equilibrio provisional, porque no suponía el hermanarse las dos vertientes que observamos en la religiosidad de Agustín. Por lo pronto, su reacción a la crisis está determinada por el optar por la argumentación filosófica, y esta preferencia estriba en el deseo de encontrar certeza. Sólo años después, cuando toma la pluma para es-

12. A. von Harnack Augustinus Confessionen, Giessen 1888. P. Afaric, L'évolution intellectuelle de saint Augustin, Paris 1918. 
cribir las Confesiones, se abrirá otra vez la fuente del lirismo religioso personal. Además, seguirán acompañándole durante toda su vida la lucha contra el traumatismo juvenil y los malos recuerdos, como tercer componente en el cuadro de los impulsos emocionales.

Para completar el paisaje hay que observar que también en otro terreno, el de la sexualidad, se hace valer la reacción, y también aquí le lleva a Agustín a una postura que le va a caracterizar por toda su vida. Es un viraje súbito y completo que, por los términos tajantes en que se viste, se da a conocer como fruto de un conflicto. En los Soliloquios (I 10,17, texto del 386-387) dice: «he decidido que no hay cosa en el mundo de la que más quiero fugarme que del acto sexual. Entiendo que no hay nada que con más fuerza pueda expulsar de su castillo al alma viril que la seducción femínea y el contacto corporal que resulta inevitable al tener esposa». «... con horror y desprecio me acuerdo de semejantes cosas». Se manifiesta así una repugnancia extrema y casi inhumana, sobre todo cuando la comparamos con el apego a la vida erótica de los años anteriores. Unos capítulos más adelante $(\mathbf{I} 14,25)$ otra vez trata del asunto, y dice (es una conversación consigo mismo): «qué sucio, qué feo, qué despreciable te pareció el abrazo de la mujer ayer, cuando comentamos el deseo de tener esposa. ... Dios te ha librado de la enfermedad y al mismo tiempo te hace ver lo que todavía te queda por curar». El texto pone en evidencia que Agustín mismo sabía que una lucha como sorda y sumergida iba a continuar por dentro. Cuando en las obras de la madurez el tema viene a la superficie, aparece muchas veces en forma de repulsión violenta, demostrando así el origen de esta actitud.

Los Diálogos de Casiciaco (De beata vita, De ordine, Contra academicos) fueron escritos bajo el impacto inmediato de la crisis emocional. Agustín los redactaba en los meses finales del año 386. Presentan un cuadro rígidamente racional. La conversación se construye, más o menos, sobre el supuesto de que se puede alcanzar toda la verdad siguiendo la sola luz de la inteligencia humana. El texto presenta ecos de los escritos de Cicerón. Sólo falta el principio específicamente escéptico de que a cada teoría puede contraponerse otra teoría que la contradiga. Se puede preguntar si todo esto no sería síntoma de un cansancio profundo después de la tormenta. El afán de construirlo todo partiendo de principios razonados se muestra también en el escrito De utilitate credendi del año 390, cuando Agustín quiere explicar qué cosa buscaba en la secta maniquea. Dice (I 2): «¿qué otra cosa me impulsaba seguir a estos hombres... si no fuera el que pretendían no forzar a ninguno a aceptar la fe si antes no hubiera sido discutida la verdad y liberada de sus ataduras?». Esto, por cierto, no puede corresponder a la realidad, sino tan sólo a los deseos de Agustín, porque de parte de los maniqueos esta reivindicación de la racionalidad no existía. Los maniqueos no tenían pretensiones filosóficas. 
En el mismo año 390 se nota el primer nuevo brote de la vertiente más bien inspirada de la religiosidad de Agustín. En el cap. 72 del escrito De vera religione dice: «No andes por fuera; vuelve a ti mismo; en el hombre interior es donde habita la verdad $\gg{ }^{13}$. Desde este año en adelante se pueden seguir las dos pistas en la obra escrita. Se dibuja muchas veces el trasfondo de una decisión tomada cuando la opción racionalista no arrojaba una suficiente seguridad. Cuando los argumentos racionales no desarrollan una fuerza suficiente para convencer y a cualquier precio se quiere alcanzar una solución, hay que refugiarse en una autoridad que pueda dar seguridad. Lo demuestra el escrito ya mencionado De utilitate credendi del año 390, en cuyo capítulo VIII 20 leemos: «este método mismo de buscar la vèrdad tenemos que aceptarlo de alguna autoridad divina». Es la misma decisión que siglos más tarde iba a tomar Erasmo, cuando el trasfondo escéptico de su pensamiento no le permitía encontrar una base suficiente para la fe y se entregaba a la autoridad de la Iglesia.

Las dos tendencias que hemos señalado siguen manifestándose en el ulterior desarrollo de Agustín. Cuando defiende su tesis contra un adversario, siempre predomina el afán de racionalizar, acompañado a menudo del afán de llevar la razón con métodos de retórica. Esto le lleva, p. ej. a una argumentación acerca de la divina justicia que, en las teorías de la predestinación, raya en un fanatismo de la razón silogística. En obras como la Ciudad de Dios, como también en otras de sus años tardíos, con una lógica estridente concluye en la existencia de una condena al fuego eterno preestablecida ${ }^{14}$. Al contrario, cuando de su corazón le vienen las palabras, como ocurre en los Sermones y en las Enarrationes in Psalmos, el calor original de los años jóvenes vuelve a la superficie ${ }^{15}$. Resulta curioso pensar que la religiosidad de Agustín recibió su primera formación en la liturgia salmódica de los maniqueos, y que cuando predicaba sus meditaciones sobre los salmos fue otra vez una poesía salmódica la que iba a embriagarle el corazón. La investigación de los últimos años va sugiriendo que el autor de las Confesiones había recibido su inspiración continua en la tradición gnóstica y dentro de la comunidad maniquea.

13. Noli foras ire; in te ipsum redi; in interiore homine habitat veritas.

14. La doutrina de la predestinación: Ciudad de Dios, XIV 10 y 15 ; XVI 1. De natura et gratia (año 415), 5 y 8 (= ed. BAC de las obras de Agustín, vol. VI p. 818, p. 822). Enchiridion (año 421), 46, 97 y 99 (= ed. BAC, vol. VI, p. 530, p. 596, p. 602). De correptione et gratia (año 426), XII 39 y XIII 42 (= ed. BAC, vol. VI, p. 186, p. 190). Opus imperfectum contra Julianum, I 57; III 38; III 84; VI 22 (= ed. BAC, vol. XXXVI, p. 84, p. 527).

15. En la introducción al volumen XVI de las obras de Agustín en la serie BAC, que contiene la Ciudad de Dios, se describe esta misma diferencia entre las dos vertientes que hemos descrito en este discurso. El autor, el agustino José Morán, indica, muy perspicazmente, que en Agustín habitan dos almas: el alma del autor de las Confesiones y la del autor de la Ciudad de Dios. 
Se me pidió añadir algunas palabras sobre Monica, la madre de Agustín. Resulta difícil hacer resaltar la figura de Mónica sin a la vez señalar los rasgos muy humanos de esta madre molesta e inspiradora. El autor inglés Peter Brown, en su biografía de Agustín (p. 406), habla de «la implacable Mónica» (the relentless Monica). En la evolución emocional de Agustín se observa un marcado paralelismo entre el apego a su madre y el problema de aceptar o no aceptar la fe católica. Por ambos lados le dominaban impulsos muy ambivalentes, determinantes del conflicto psíquico que llevaba dentro. En el libro V de las Confesiones nos cuenta cómo quería ponerse a salvo de la presencia de Mónica, engañándola acerca de su salida de África: «el viento hinchó las velas y desapareció la playa en la que dejé a mi madre desesperada». Iba a Roma como un nuevo Eneas dejando en Cartago a Didón. La madre no se dejó vencer y le siguió algún tiempo después a Milán, pese a los peligros del mar y un largo y penoso viaje. Cuando ya se dibujaban al horizonte las señales de la tempestad emocional que iba a desencadenarse en la crisis del 386, un episodio muy triste fue organizado por Mónica. Nos lo cuenta Agustín en Confesiones VI 13-15. La mujer con la que había vivido con toda fidelidad por 14 años, madre de su hijo Adeodato, fue despedida sin más y volvió a Cartago. Es la clásica figura de la suegra que expulsa a la nuera de casa. Con todo, en Agustín también se mantuvo el otro componente del apego a la madre. Acompañó a Mónica en sus últimos días cuando murió en Ostia. En los libros X-XI-XIIXIII de las Confesiones, que añadió a la autobiografía para dar vuelta a sus convicciones, describe en términos líricos su esperada vuelta a la Jerusalén celeste como un volver a casa. Rezando a Dios dice: «que no me deje extraviarme más, hasta que en la paz de esta madre queridísima, en la que están las primicias de mi espíritu, recojas todo lo que soy» (XII 16,23). Al describir la patria del alma como una «madre en la que están las primicias de mi espíritu», la expresión por sí misma se refiere a la Jerusalén celeste, pero en el trasfondo se observa el recuerdo de Mónica, que había estado de madrina de su fe cristiana.

Th. G. SINNIGE 